\title{
RETRACTED ARTICLE: Screening research on membrane protein of dermal stem/progenitor cells with different differentiation potential
}

\author{
Fuguo Chen $\cdot$ Xiaoping Zhang $\cdot$ Dan Bi $\cdot$ \\ Linlin Xia $\cdot$ Yang Lin $\cdot$ Wenjie Zhang • \\ Wei Liu • Yilin Cao
}

Received: 22 October 2011 / Accepted: 8 June 2012/Published online: 10 March 2013

(C) Springer Science+Business Media B.V. 2014

This article has been retracted at the request of the corresponding author as it was submitted to the journal without the prior permission of all the authors.

F. Chen $(\bowtie) \cdot$ D. Bi $\cdot$ L. Xia · W. Zhang ·

W. Liu · Y. Cao $(\bowtie)$

Department of Plastic and Reconstructive Surgery, Shanghai 9th People's Hospital, Shanghai Stem Cell Institute, Shanghai Jiao Tong University School of Medicine, Shanghai Key Laboratory of Tissue Engineering, No.639 Zhi Zaoju Road, Shanghai 200011, People's Republic of China

e-mail: michaelin@sjtu.edu.cn

Y. Cao

e-mail: chenfg5118@126.com

\section{Zhang $\cdot$ Y. Lin}

Department of Nuclear Medicine, Shanghai 10th People's

Hospital, Tongji University School of Medicine,

Shanghai 200072, People's Republic of China 